\section{Infra-Red Dichroism of Nylon and Polyethylene Terephthalate}

IN this laboratory we have been studying for some time the polarized infra-red spectra of single fibres and filaments. A 0.78 N.A. reflecting microscope of our own design, used with a Perkin-Elmer Model 12- $C$ infra-red spectrometer in an arrangement similar to that of Blout, Bird and Grey', has allowed examination of specimens as narrow as 20 microns in width. Polarized radiation was obtained with a silver chloride sheet transmission polarizer. The very thin specimens required for the fundamental region of the spectrum were prepared by either longitudinally sectioning or mechanically flattening the single fibres.

A series of drawn specimens of nylon 66 and polyethylene terephthalate, kindly supplied by E. I. du Pont de Nemours and Co., Inc., have yielded results of particular interest. A summary of dichroic ratios observed for a number of absorption bands in specimens of different (nominal) draw ratio is given in Table 1. Each value represents the average of measurements made on 8-15 single filaments, and has been corrected for scattering losses, but not for the effect of beam convergence in the reflecting microscope. We have found that the latter correction is small, and does not alter the general results. It was also established that no appreciable double orientation was present in the specimens.

Table 1. DICHROId RATIO $\left(\varepsilon_{\boldsymbol{\pi}} / \varepsilon_{\sigma}\right)$

\begin{tabular}{|c|c|c|c|c|c|c|c|}
\hline & \multirow{2}{*}{ cm..$^{-1}$} & \multicolumn{6}{|c|}{ Draw ratio } \\
\hline & & 1 & $2 \cdot 02$ & $2 \cdot 99$ & $3 \cdot 99$ & $5 \cdot 02$ & $5 \cdot 99$ \\
\hline Nylon 66 & $\begin{array}{l}3,310 \\
3,075 \\
2,930 \\
2,860\end{array}$ & $\begin{array}{l}0.98 \\
1.37 \\
0.92 \\
0.98\end{array}$ & $\begin{array}{l}1 \cdot 35 \\
1 \cdot 86 \\
1 \cdot 23 \\
1 \cdot 34\end{array}$ & $\begin{array}{l}1 \cdot 25 \\
0 \cdot 74 \\
1 \cdot 20 \\
1 \cdot 13\end{array}$ & $\begin{array}{l}0.92 \\
0.42 \\
0.96 \\
0.80\end{array}$ & $\begin{array}{l}0.79 \\
0.42 \\
0.90 \\
0.77\end{array}$ & $\begin{array}{l}0.84 \\
0.46 \\
0.99 \\
0.78\end{array}$ \\
\hline $\begin{array}{l}\text { Polyethylene } \\
\text { terephthalate }\end{array}$ & $\begin{array}{r}1,021 \\
975\end{array}$ & $\begin{array}{l}0.88 \\
0.43\end{array}$ & $\begin{array}{l}0.98 \\
1.61\end{array}$ & $\begin{array}{l}1 \cdot 17 \\
2 \cdot 04\end{array}$ & $\begin{array}{l}1 \cdot 46 \\
3 \cdot 43\end{array}$ & $\begin{array}{l}1 \cdot 69 \\
3 \cdot 92\end{array}$ & $\begin{array}{l}1 \cdot 53 \\
3 \cdot 63\end{array}$ \\
\hline
\end{tabular}

It is seen that the four nylon absorption bands exhibit parallel dichroism at the lower draw ratios, and change over to perpendieular dichroism as the drawing proceeds. Hitherto, only perpendicular dichroism has been observed for these bands in highly oriented films $\mathrm{m}^{2,3}$. The $3,310 \mathrm{~cm}^{-1} \mathrm{~N}-\mathrm{H}$ stretching vibration and the two methylene stretching motions at 2,930 and $2,860 \mathrm{~cm}^{-1}$ change dichroism in unison, as would be expected since the corresponding transition moments are all perpendicular to the chain axes. The $3,075 \mathrm{~cm} .^{-1}$ band, the assignment of which is still in doubt, exhibits greater extremes in dichroic ratio, and changes from parallel to perpendicular character at an earlier stage. At draw ratios of 1 and 2 there is evidence that the extent of parallel dichroism for the $3,075 \mathrm{~cm}^{-1}$ band may be affected by the degree to which the filaments are flattened prior to infra-red examination 4 . This effect has not been observed for the other three bands of nylon 66.

We have observed that the change in dichroic character at about draw ratio 2.02 is quite general throughout the spectrum of polyethylene terephthalate. In addition to the 1,021 and $975 \mathrm{~cm}^{-1}$ bands, at least six other bands in the region $1,500-700 \mathrm{~cm} .^{-1}$ reverse their initial dichroism as a result of drawing. The dichroism of the highly drawn filaments agrees in general with the results of Miller and Willis ${ }^{5}$.

In the nominally undrawn condition (draw ratio 1 ), dichroism was found to be present in the polyethylene terephthalate, and to a lesser extent in the nylon, even though the undrawn filaments of both showed very low birefringence. The X-ray patterns of undrawn nylon indicated an unoriented, crystalline structure; on drawing, orientation was induced but with little change in crystallinity. The polyethylene terephthalate, initially amorphous, developed crystallinity on drawing, most markedly between draw ratios 2.99 and 3.99 , where an inflexion in its birefringence curve appeared. In neither material, however, did $\mathrm{X}$-ray patterns or birefringence measurements give evidence of a major reversal of chain orientation which the infra-red results alone might imply.

These results indicate that measurements of infrared dichroism of fibres may reveal chain orientation which is not detected by the usual $\mathrm{X}$-ray and optical techniques. Holmes et al. ${ }^{6}$ have reported that the amorphous regions in stretched polyethylene film are oriented at nearly right angles to the crystalline regions. It is possible that in poorly oriented fibre specimens the amorphous regions have a chain orientation quite different from that attained in the fully drawn, crystalline material, and that at the lower extensions the orientation of the emorphous regions largely determines the infra-red dichroism. Keller's recent suggestion ${ }^{7}$ of helical structures in synthetic polymers offers another very attractive explanation of some of these results, and is being investigated further.

\section{RICHARD G. QUYNN} Riohard STEELE

Textile Research Institute, Princeton, New Jersey. Feb. 6.

${ }^{1}$ Blout, E. R., Bird, G. R., and Grey, D. S., J. Opt. Soc. Amer., 40, 306 (1950).

${ }^{2}$ Ambrose, E. J., Elliot, A., and Temple, R. B., Proc. Roy. Soc., A, 199,183 (1949).

- Bamford, C. H., et al., Proc. Roy. Soc., B, 141, 49 (1953).

- Caroti, G., and Dusenbury, J. H. (private communication; 'Textile Research Institute).

${ }^{5}$ Miller, R. G. J., and Willis, H. A., Trans. Farad. Soc., 49, 433 (1953). Bolmes, D. R., et al., 121, 1104 (1953).

' Keller, A., J. Polymer Sci., 11, 567 (1953).

\section{Rotational Analysis of the Columbium Oxide Bands}

IN a previous communication ${ }^{1}$, the rotational constants determined for the ground and excited states of the columbium oxide molecule have been reported as derived from the rotational analysis of the three bands $\lambda 4,510(1,0), \lambda 4,689(0,0)$ and $\lambda 4,915$ $(0,1)$. Due to an error, which has unfortunately crept in, in the calculation of the $r_{e}$ values, it has since been found necessary to revise the analysis and to redetermine the constants. This work has been carried out. The two $R$ and the two $P$ branches and the $K$-numbering have been confirmed from the combination relationships. The revised rotational constants are :
${B^{\prime}}^{\prime}=0.3447 \mathrm{~cm} .^{-1}$
$B^{\prime}=0.3420$
$\begin{aligned} B^{\prime} e^{\prime} & =0 \cdot 3461, \\ a^{\prime}=0.0027 & \end{aligned}$
$\begin{aligned} B^{\prime \prime \prime} & =0.3746, ", \\ B^{\prime \prime} \theta & =0.3791,\end{aligned}$

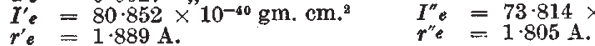

The $D$-values are of the order of $10^{-7} \mathrm{~cm} .^{-1}$.

Full details of this analysis will be published elsewhere.

Physics Department,

K. Suryanarayana Rao

Andhra University,

Waltair. Feb. 17.

${ }^{2}$ Rao, K. S., Nature, 170, 670 (1952). 